\section{CRYSTAL ENGINEERING OF QUERCETIN BY LIQUID ASSISTED GRINDING METHOD}

\author{
Umi Athiyah, Putu Andika Kusuma, Tutik, Maria L. A. D. Lestari, Dewi \\ Isadiartuti, Diajeng Putri Paramita, Dwi Setyawan*
}

Faculty of Pharmacy, Universitas Airlangga, Surabaya, Indonesia
Article history

Received

5 April 2018

Received in revised form

2 August 2018

Accepted

30 August 2018

Published online

15 December 2018

*Corresponding author

dwisetyawan-

90@ff.unair.ac.id
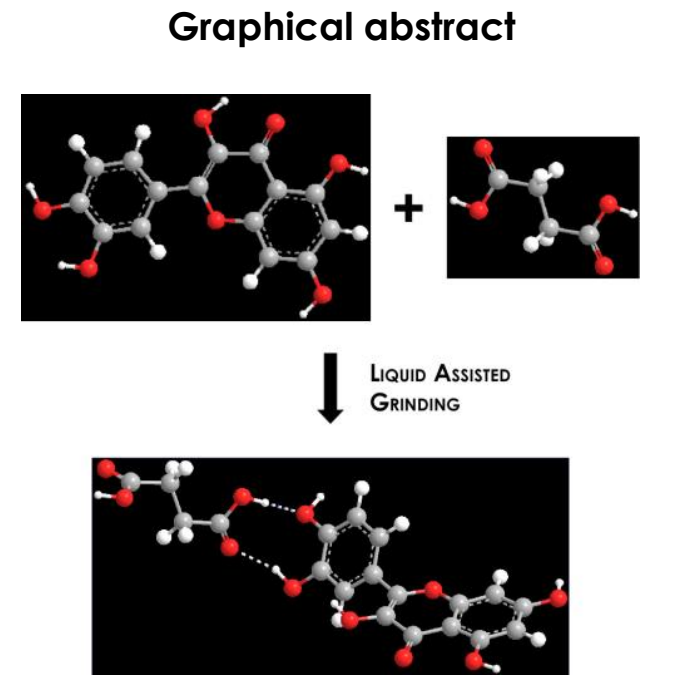

\begin{abstract}
Quercetin has been proposed to exhibit numerous pharmacological benefits yet suffer low bioavailability due to the extremely low solubility. A research to study the impact of cocrystallization of quercetin with succinic acid on the solubility and dissolution profile has been performed. Cocrystallization in molar stoichiometry of 1:1 was carried out via liquid assisted grinding with methanol in ball milling apparatus. Cocrystal formation was identified by hot stage microscopy (HSM) at first, then cocrystal phase was characterized using differential thermal analysis (DTA), powder X-ray diffractometry (PXRD), scanning electron microscopy (SEM), and fourier-transform infrared (FT-IR) spectroscopy. Solubility and dissolution test were conducted as well. DTA thermogram exhibits new endothermic peak at $280.32^{\circ} \mathrm{C}$ representing the melting point of cocrystal phase alongside with endothermic point of pure compounds. Powder X-ray diffractograms show new diffraction peaks on behalf of cocrystal formation at $2 \theta=8.92,9.88,13.04,29.78,35.21^{\circ}$. FT-IR spectroscopy reveals band shifting in $-\mathrm{OH}$ group region. On SEM photographs, one can observe crystal habit of succinic acid being covered by crystal with different habit. This indicates that quercetin interacts with succinic acid only on the surfaces and causes imperfect formation of cocrystal phase. Cocrystallization quercetin improves solubility by 1.62 times higher and dissolution rate by 1.25 higher than pure quercetin (one-way ANOVA, $p<0.05$ ).

Keywords: Cocrystal, quercetin, liquid assisted grinding, characterization, solubility
\end{abstract}

C 2019 Penerbit UTM Press. All rights reserved

\subsection{INTRODUCTION}

Cocrystal is a multicomponent crystalline consisting of two or more different components held by hydrogen bonding in well-defined stoichiometry ratio $[1,2]$. In the recent pharmaceutical field, cocrystal engineering has been used as an alternative approach to modify solid phase of active pharmaceutical ingredient(s) (APIs) in order of improving API's physicochemical properties including solubility, dissolution rate, mechanical properties, hygroscopicity, physical and chemical stability. The term pharmaceutical cocrystal has been introduced then for the cocrystal formed between an API and a cocrystal former (coformer) and it has shown the advantages as compared to amorphous and salt modification [2-4].

Cocrystal can be prepared using various techniques e.g. solution crystallization (solvent evaporation, antisolvent method), mechanical 
grinding (dry or liquid assisted), melt-extrusion, slurry, supercritical fluid, wet and dry compression $[5,6]$. Grinding method is generally employed method to form cocrystal. It has been known to possess major advantages over the other techniques, including more environmentally friendly method for industrial scale production due to absence or small amount of solvent. The process is independent to temperature and formation of unwanted solvate can be avoided $[6,7]$. Grinding with liquid assisting provides faster formation of cocrystal phase in greater degree of crystallinity than dry grinding. It has been determined to be the role of the liquid (solvent) to provide local saturated solution needed to form cocrystal phase [8].

Quercetin (3,3', 4',5,7-pentahydroxylflavone), a versatile molecule belongs to flavonoids subclass, has been well-known to have numerous pharmacological activities, including antioxidant, antiviral, anticancer, antimicrobial, antiinflammatory, cardioprotective, hepatoprotective, chemopreventive, and anticarcinogenic [9, 10]. Despite of the remarkable potential, quercetin suffers low bioavailability due to the extremely low aqueous solubility and the susceptibility to metabolic conjugation [11].

Quercetin has five hydroxyl groups that can be both hydrogen donor and hydrogen acceptor as well as other two hydrogen acceptors those are aromatic cyclic oxygen and keto group. These groups are capable of hydrogen bonding with complementary groups from different molecule [12]. Therefore, cocystal engineering appears to be the most promising approach to improve quercetin properties [11-14]. Succinic acid is frequently used as coformer in cocrystallization of API [14-17] as it has two carboxylic groups at each end that can form hydrogen bond and is considered to be "generally recognized as safe" (GRAS) [17].

In this research, cocrystal quercetin-succinic acid with stoichiometry 1:1 was prepared using liquid assisted grinding method. Cocrystal formation was identified with hot stage microscopy (HSM). Physical characterizations were performed using differential thermal analysis (DTA), powder X-ray diffractometry (PXRD), scanning electron microscopy (SEM), and fourier-transform infrared (FT-IR) spectroscopy. Solubility and dissolution profile were also reported.

\subsection{METHODOLOGY}

\subsection{Materials}

Quercetin was obtained from Tokyo Chemical Industry Co., Ltd., Japan (Lot No. 83N20) as monohydrate species and succinic acid was purchased from Merck, Austria. Other used materials were sodium lauryl sulphate, citric acid, sodium hydroxide, and pro-analytical methanol (from EMerck, Germany).

\subsection{Identification of Cocrystal Formation}

Cocrystal formation was identified using hot stage microscopy (HSM) instrumentation equipped with polarized microscope and hot stage. First, the higher melting compound quercetin was placed on microscope object glass and heated until the solid melted to occupy half the area under cover glass. After the melt had been solidified, the lower melting compound succinic acid was placed near to quercetin solid at the edge of cover glass. Then the sample was heated. As succinic acid melted, it was drawn under the cover glass and contacted with quercetin solid. The sample was allowed to cool. The area where two compounds contacted is called the mixing zone and it was observed under polarized microscope with magnification of 40 .

\subsection{Preparation of Quercetin-succinic Acid Physical Mixture}

Physical mixture of quercetin and succinic acid was prepared by mixing homogenously the pure compounds which were weighed equimolarly according to $1: 1$ stoichiometry.

\subsection{Preparation of Quercetin-Succinic Acid Cocrystal}

Cocrystal of quercetin and succinic acid was prepared from liquid assisted grinding method. Ball milling apparatus with aluminium oxide balls and methanol as assisting liquid were used for this purpose. Each quercetin and succinic acid were weighed equimolarly. Both pure compounds, $20 \%$ $(\mathrm{w} / \mathrm{v})$ solvent methanol, and twelve balls were inserted into the grinding jar then it was closed tightly. Ball milling was set for thirty minutes running. The grinded solid was removed into vial covered by aluminium foil.

\subsection{Differential Thermal Analysis (DTA)}

Thermal analysis was performed by differential thermal analyser (Mettler Toledo FP 85, Switzerland). Sample weighed about $5 \mathrm{mg}$ was heated in hermetically sealed aluminium pan with temperature range of $30-350^{\circ} \mathrm{C}$ and heating rate of $10^{\circ} \mathrm{C} / \mathrm{min}$.

\subsection{Powder X-Ray Diffraction (PXRD)}

Powder diffractograms were collected using Phillips $X$ 'Pert diffractometer, Netherland with CuK $\alpha$ radiation (1.54 $\AA$ ). Electricity condition was set at 40 $\mathrm{kV}$ and $30 \mathrm{~mA}$. Each sample was placed and surface-flattened in the sample holder for scanning over $2 \theta$ range of $5-40^{\circ}$ and step size $0.017^{\circ}$. The obtained diffractograms were compared between samples and analysed. 


\subsection{Fourier-Transform Infrared Spectroscopy (FT-IR)}

FT-IR spectra were measured using Jasco 5300 FT-IR spectrometer, USA. Each sample was mixed homogeneously with potassium bromide powder. The mixture was compressed by hydraulic press to form transparent disc. The disc was placed on sample holder and shot by IR beam. Each spectrum was recorded from 4000 to $400 \mathrm{~cm}^{-1}$.

\subsection{Scanning Electron Microscopy (SEM)}

Scanning electron-micrograph of each sample was captured using JEOL instrumentation, Japan. Sample was placed on the holder and coated with gold aluminium by thickness of $10 \mathrm{~nm}$. Photomicrographs were taken at 600 and 1500 magnification in electricity condition of $20 \mathrm{kV}$ and $12 \mathrm{~mA}$.

\subsection{Solubility Test}

Solubility test was performed in citrate buffer $\mathrm{pH}$ $5.0+0.5$ (prepared from citric acid and sodium hydroxide) and at temperature of $30 \pm 0.5^{\circ} \mathrm{C}$. Each sample weighed equivalent to $20 \mathrm{mg}$ quercetin was suspended in $40 \mathrm{~mL}$ buffer solution and stirred using a magnetic stirrer at speed of 600 rpm for 3 hours. The final solution was filtered through $0.45 \mu \mathrm{m}$ filter membrane. $4 \mathrm{~mL}$ filtered solution was taken to be spiked with $1 \mathrm{~mL}$ quercetin standard solution $10 \mathrm{ppm}$. The absorbance then was measured using UV-Vis spectrophotometry at the maximum wavelength of quercetin $(336.95 \mathrm{~nm})$. \% solubility (w/v) was analysed statistically with one-way ANOVA $\alpha=0.05$.

\subsection{In Vitro Dissolution Test}

Dissolution test was conducted using USP II (paddle) apparatus in citrate buffer solution containing $2 \%$ sodium lauryl sulphate at temperature $37+/-0.5^{\circ} \mathrm{C}$. Sample was weighed equivalent to $20 \mathrm{mg}$ quercetin and stirred in $100 \mathrm{rpm}$ for 60 minutes. $5.0 \mathrm{~mL}$ sample was withdrawn at $5,10,15,30,45$, and 60 minutes then filtered afterward through 0.45 filter membrane. Quercetin concentration was measured by UV-Vis spectrophotometry at the maximum wavelength for quercetin with aid of standard curve. The calculated data includes dissolved percentage (\%) and dissolution efficiency within 60 minutes (DE60). Statistical analysis was calculated with one-way ANOVA $\alpha=0.05$.

\subsection{RESULTS AND DISCUSSION}

\subsection{Identification of Cocrystal Formation}

HSM is usually used in screening of interaction as it can identify phase behaviour of binary system in a function of temperature. Under polarized microscope observation, only crystalline phases will be visible because they direct the polarized light and they can exhibit different colour and intensity. Formation of new crystalline phase can lead to different crystal habit observed during experiment [18, 19]. HSM study resulted in distinctive crystal habit between quercetin and succinic acid as it is shown in Figure 1 ( $A$ and $B$, respectively). In the mixing zone (Figure $1 C$ ), a new crystal habit was observed (Figure 1C, pointed by arrow). This result indicates cocrystal formation between quercetin and succinic acid.
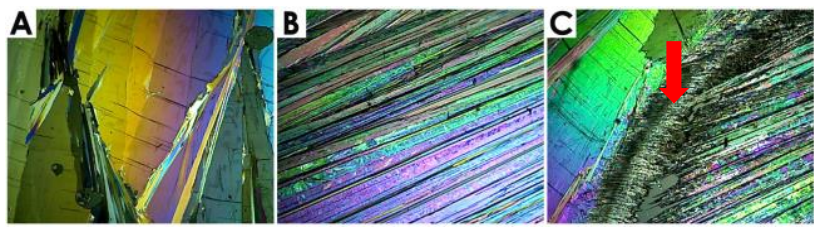

Figure 1 HSM photomicrographs for crystal habit of (A) quercetin, (B) succinic acid, and (C) the mixing zone in magnification of 40 "Red arrow points new formed habit"

\subsection{Differential Thermal Analysis (DTA)}

Thermograms of pure compounds quercetin and succinic acid, and cocrystal phase were shown in Figure 2. Quercetin exhibits two endothermic events: first peak $\sim 120^{\circ} \mathrm{C}$ denotes dehydration process while second peak at $321.92^{\circ} \mathrm{C}$ represents melting point (Figure 2A). The other hand, succinic acid exhibits only one individual endothermic peak at $187.87^{\circ} \mathrm{C}$ (Figure 2B). It is quite interesting to observe thermogram of cocrystal phase that shows all those three peaks with a new one at $280.32^{\circ} \mathrm{C}$. This new peak belongs to different phase formed from interaction of quercetin and succinic acid, i.e. cocrystal formation. However, the peak is too broad to observe an endothermic event. Our concomitant liquid assisted grinding experiment using ethanol showed similar thermogram's pattern (without the peak of dehydration) and it clearly exhibited a new endothermic peak at $282,41^{\circ} \mathrm{C}$ (unpublished data). So, it can be concluded definitively that new crystalline phase has been formed which melts around $280^{\circ} \mathrm{C}$. Appearance of peak of quercetin and succinic acid in the same thermogram suggests that the cocrystal phase formed incompletely. 


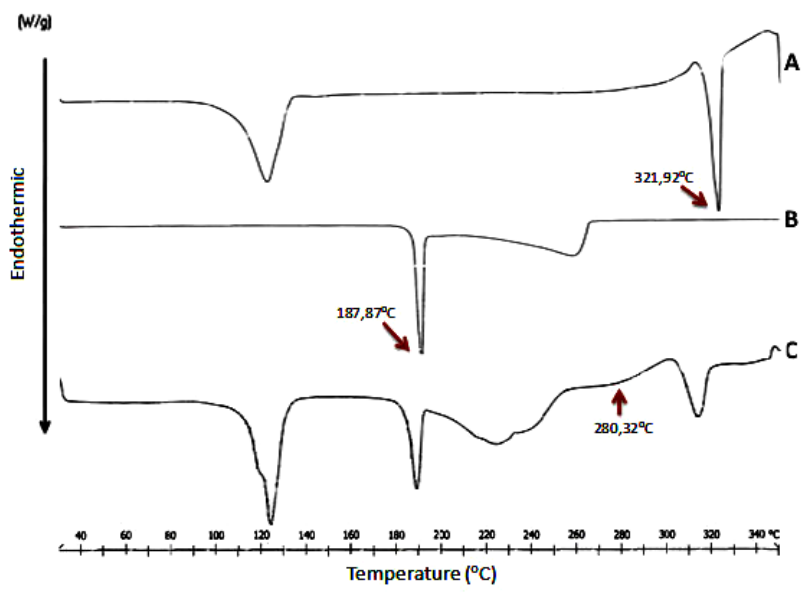

Figure 2 Thermograms of (A) quercetin, (B) succinic acid, and $(C)$ cocrystal phase (the arrows denote the melting point)

\subsection{Powder X-Ray Diffractometry (PXRD)}

Diffraction profiles were collected for pure compounds quercetin and succinic acid, physical mixture, and cocrystal phase. Comparison of each profile can be seen in Figure 3. Quercetin shows specific strong peaks at $2 \theta=10.78,12.43,14.15,27.41^{\circ}$ (Figure 3A). Succinic acid has diffraction peaks at $2 \theta=16.02, \quad 19.99,26.10,31.41,32.40^{\circ}$ (Figure 3B). Interferences of quercetin and succinic acid appear on diffractogram of physical mixture (Figure $3 \mathrm{C}$ ). Cocrystal phase shows diffraction profile with six new peaks at $2 \theta=8.92,9.88,13.04,29.78,35.21^{\circ}$ (Figure 3D). PXRD result indicates change in crystal lattice due to interaction between quercetin and succinic acid to form cocrystal.

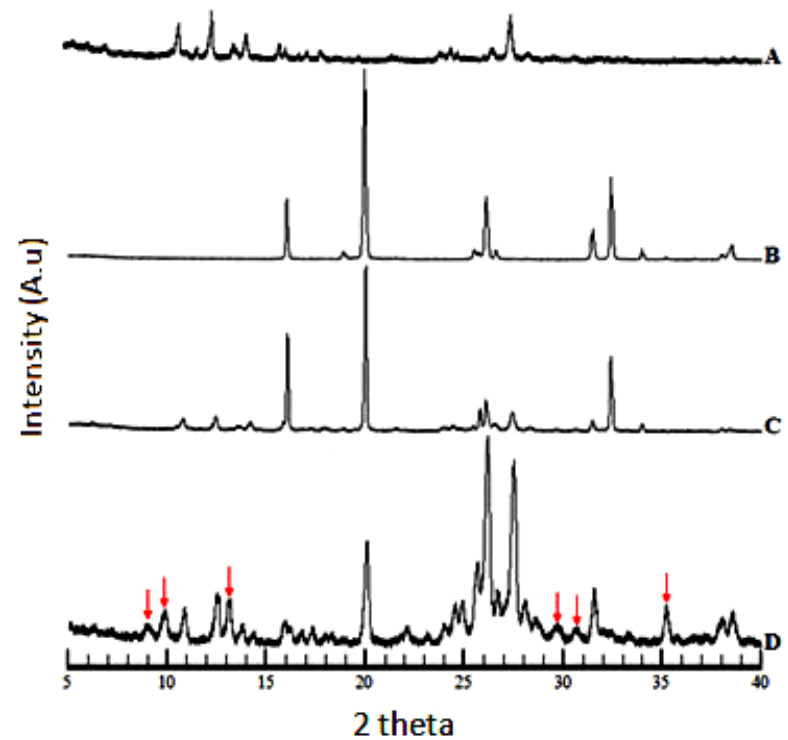

Figure 3 Diffractograms of (A) quercetin, (B) succinic acid, (C) physical mixture, and (D) cocrystal phase (the arrows denote new peaks)

\subsection{Fourier-Transform Infrared Spectroscopy (FT-IR)}

IR spectra of quercetin, succinic acid, physical mixture, and cocrystal phase are shown in Figure 4. Quercetin and succinic acid both have definite absorbance profile (Figure $4 \mathrm{~A}$ and $\mathrm{B}$ respectively). Physical mixture exhibits superimposed absorbance of quercetin and succinic acid (Figure 4C) as no interaction occurs between pure compounds [20, 21].

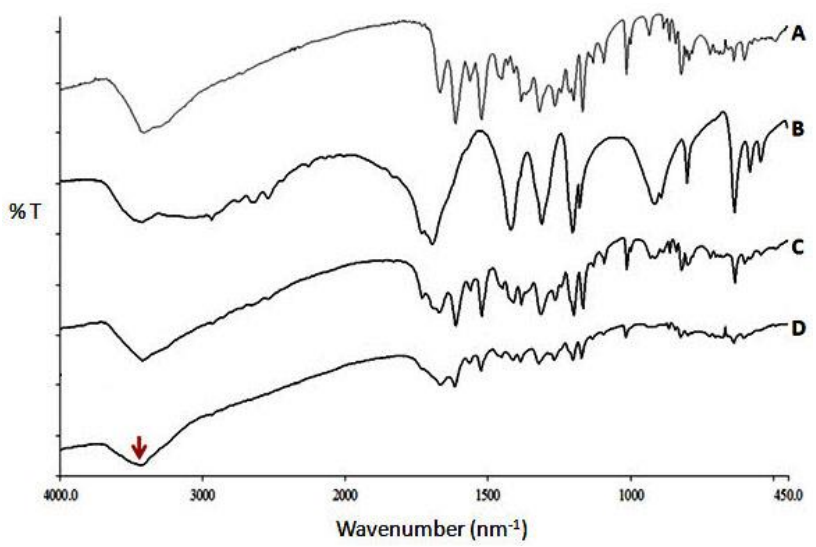

Figure 4 Spectra of (A) quercetin, (B) succinic acid, (C) physical mixture, and (D) cocrystal phase (the arrow denotes band shifting)

One can see band shifting in $-\mathrm{OH}$ group region in the spectrum of cocrystal phase (Figure 4D). $-\mathrm{OH}$ peak of quercetin shifted to $3430 \mathrm{~cm}^{-1}$ from its original position in $3411 \mathrm{~cm}^{-1}$. Decrease in intensity of $-\mathrm{OH}$ group region is also observed (transmittance of $14 \%$ in quercetin's increased to $26 \%$ in cocrystal's spectra). Decrease in intensity, peak loss, and band shifting or appearance of new peak in IR observation characterize cocrystal formation [13, 22]. Band shifting in $-\mathrm{OH}$ group region is caused by change in hydrogen bonding in the cocrystal phase that hydroxyl group of quercetin is hydrogen-bonded to carboxylic group of succinic acid. This prediction comes along with structural image drawn using Chem3D® Pro 12.0 (Figure 5). Total energy bonding of cocrystal structure was calculated as -3.7767 $\mathrm{kcal} / \mathrm{mol}$. It is predicted that cocrystal phase has lower potential energy (negative value) which is thermodynamically more stable and tends to form. However, this predicted structure may unable to pack in ordered crystalline structure as this prediction does not consider hydrogen bonding competition amongst functional groups of each component (5). 


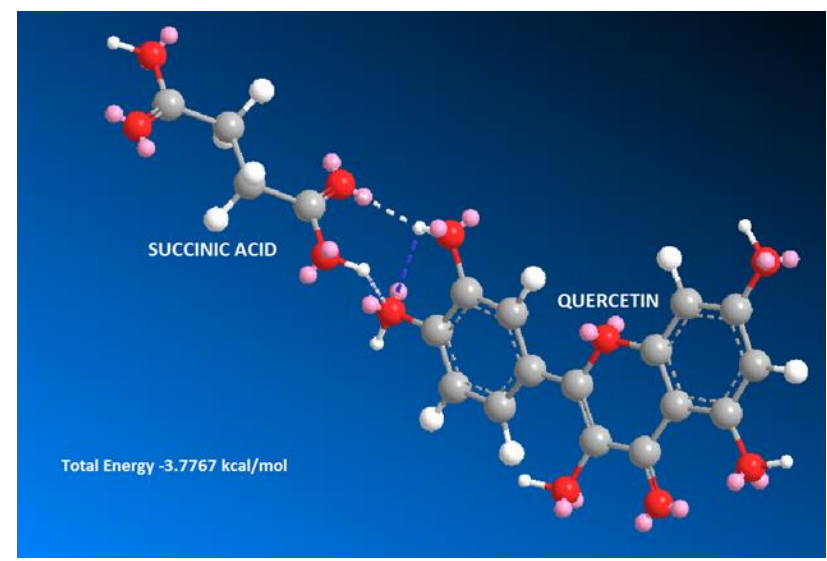

Figure 5 Prediction of hydrogen bonding between molecule of quercetin and succinic acid. Dashed lines represent hydrogen bonding of hydroxyl group on quercetin molecule with carboxylic group on succinic acid molecule

\subsection{Scanning Electron Microscopy (SEM)}

Crystal morphology of each sample can be seen in Figure 6. Micrograph of succinic acid was taken at magnification of 600 while the other two at 1500. It was due to enormous size of succinic acid's crystal that the habit cannot be observed clearly in higher magnification. Photograph of quercetin shows columnar habit in large range of particle size (Figure 6A) which agrees with previously reported result [23, 24]. Succinic acid has layered shape (Figure 6B).

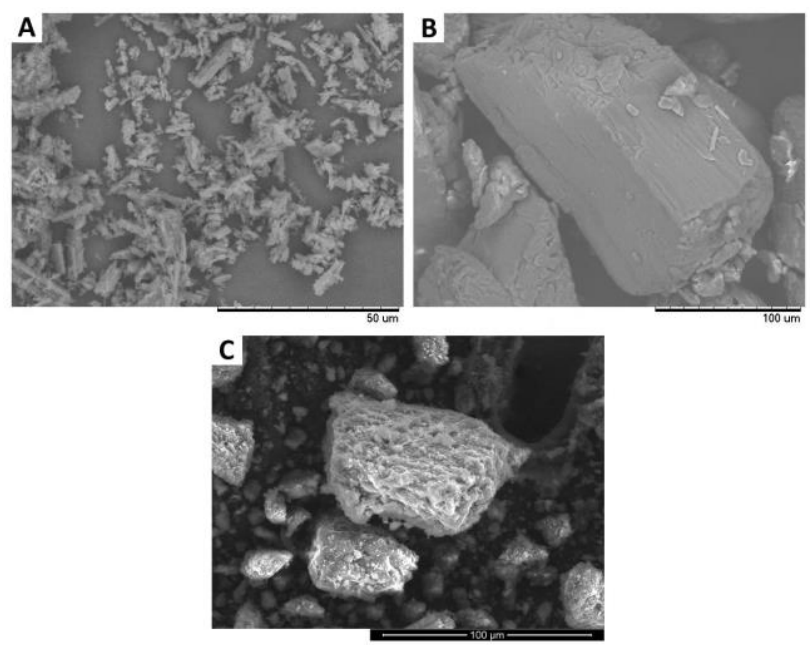

Figure 6 SEM micrographs of (A) quercetin, (B) succinic acid, and $(C)$ cocrystal phase. Quercetin and cocrystal phase were observed under magnification of 1500 and succinic acid in magnification of 600

SEM analysis on cocrystal phase resulted in change in morphology of both pure compounds (Figure 6C). One can see a crystal having the habit of succinic acid covered in smaller crystals with different habit and the habit of quercetin isn't observed at all. It is likely that succinic acid retains its habit but quercetin losses the previous habit to form the new one in the surface of succinic acid crystal.

In liquid assisted grinding method, grinding leads to cocrystallization by generating amorphous solid and the liquid (solvent) extends the interaction by dissolving the solid to facilitate molecular diffusion $[25,26]$. However, limited amount of solvent may impact the process that does not proceed completely as it is seen in the SEM micrographs that interaction between quercetin and succinic acid only occur in the interface.

\subsection{Solubility Test}

Solubility test was conducted at $\mathrm{pH} 5$ using buffer citrate due to quercetin instability in solution with $\mathrm{pH}$ under 5 (rapidly degraded) $[27,28]$. The standard curve was prepared beforehand, and the regression line obtained was $y=0.0664 x+0.0125$ with correlation coefficient of 0.9997 . Absorbance measured in the test was too low (less than 0.1) to comply accuracy parameter in UV-Vis spectrophotometry measurement. So, each sample was spiked with quercetin standard solution. Result of solubility test for quercetin, physical mixture, and cocrystal phase (the mean of triplicate measurements) were $0.94+/-0.02 ; 1.22+/-0.02$; and $1.57+/-0.04\left(\times 10^{-4} \% \mathrm{w} / \mathrm{v}\right)$ respectively.

Physical mixture shows higher solubility than pure quercetin. It can be explained that quercetin is dispersed in succinic acid which the latter has better aqueous solubility. However, as no interaction occurs in physical mixture, increase in solubility is not as significant as in cocrystal phase that involved noncovalent interaction between different molecules. Cocrystal formation for quercetin has been known to improve the solubility in water $[11,12]$. Cocrystal formation can generate lattice that has lower bonding energy than the previous one and can improve affinity of API with solvent that make cocrystal phase of quercetin having higher solubility in water $[13,29]$.

\subsection{In Vitro Dissolution Test}

Surfactant sodium lauryl sulphate was used in dissolution test to improve solubility and wettability of API by lowering surface tension between solid and liquid phase so that sink condition can be achieved. Surfactant used in dissolution test imitates bile acid in the gastrointestinal tract that acts as surfactant to facilitate diffusion and transport of the solute [30]. 


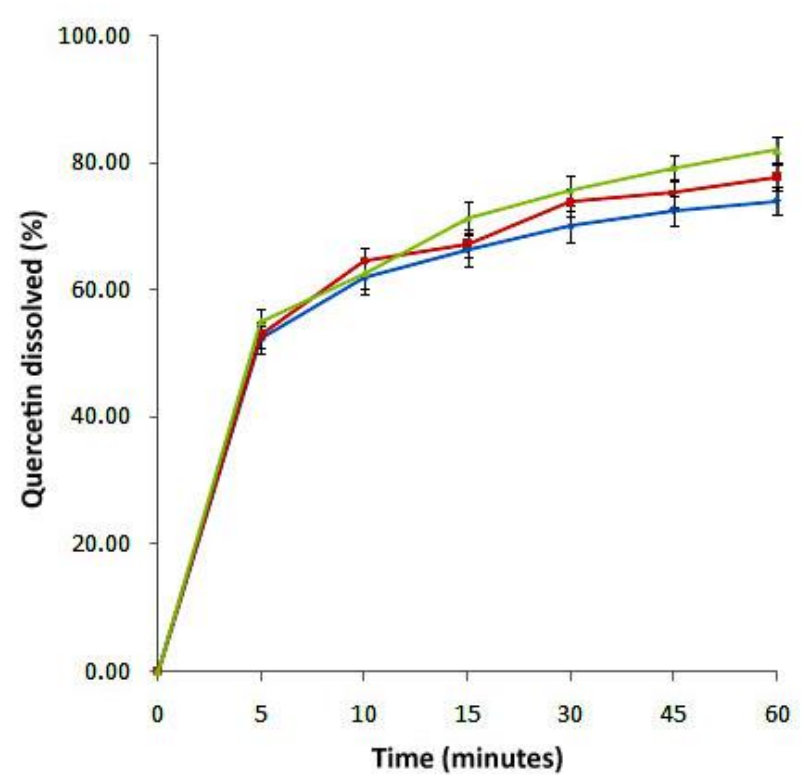

Figure 7 Dissolution of quercetin (blue line), physical mixture (red line), and cocrystal phase (green line)

Figure 7 shows dissolution profile of quercetin, physical mixture, and cocrystal phase. Physical mixture and cocrystal phase exhibit improved dissolution rate compared to pure quercetin, respectively 1.02 and 1.25 higher. This improvement is related to higher solubility shown by physical mixture and cocrystal phase (previous section). According to Noyes-Whitney equation, dissolution rate will increase if saturated concentration is increased [31].

\subsection{CONCLUSION}

In this research, quercetin has been confirmed to form cocrystal with succinic acid via liquid assisted grinding, however, incompletely. Formation of cocrystal leads to different physicochemical properties. Cocrystal phase exhibits new endothermic peak and diffraction peaks in DTA and PXRD study, respectively. IR spectra shows band shifting in $-\mathrm{OH}$ group region and SEM study results in different crystal morphology. Cocrystal of quercetinsuccinic acid has been known to slightly improve aqueous solubility and dissolution rate of quercetin.

\section{Acknowledgement}

The authors acknowledged to Ministry of Research, Technology, and Higher Education for granted funding through Penelitian Terapan Unggulan Perguruan Tinggi (PTUPT), No: 004/ADD/SP2H/LT/DRPM/VIII/2017.

\section{References}

[1] Vishweshwar, P., McMahon, J. A., Bis, J. A., and Zaworotko, M. J. 2006. Pharmaceutical Co-Crystals. Journal of Pharmaceutical Sciences. 95(3): 499-516. DOI: http://dx.doi.org/10.1002/jps.20578.

[2] Shan, N. and Zaworotko, M. J. 2010. Polymorphic Crystal Forms and Cocrystals in Drug Delivery (Crystal Engineering). In Burger's Medicinal Chemistry, Drug Discovery, and Development $7^{\text {th }}$ Edition. 187-218.

DOI: https://doi.org/10.1002/0471266949.bmc156.

[3] Kothur, R. R., Swetha, A. S., and Bondili, N. P. 2012. An Outline of Cocrystal Engineering of Pharmaceutical Cocrystals and Applications: A Review. International Journal of Pharmaceutical Research and Development. 4(08): 084-092.

[4] Schultheiss, N. and Newman, A. 2009. Pharmaceutical Cocrystals and Their Physicochemical Properties. Crystal Growth \& Design. 9(6): 2950-2967. DOI: http://dx.doi.org/10.1021/cg900129f.

[5] Thakuria, R., Delori, A., Jones, W., Lipert, M. P., Roy, L., and Rodríguez-Hornedo,N. 2013. Pharmaceutical Cocrystals and Poorly Soluble Drugs. International Journal of Pharmaceutics. 453: 101-125. DOI: http://dx.doi.org/10.1016/j.jipharm.2012.10.043.

[6] Douroumis, D., Ross, S. A., and Nokhodchi, A. 2017. Advanced Methodologies for Cocrystal Synthesis. Advanced Drug Delivery Reviews. DOI: http://dx.doi.org/10.1016/j.addr.2017.07.008.

[7] Trask, A. V. and Jones, W. 2005. Crystal Engineering of Organic Cocrystals by the Solid-State Grinding Approach. Topics in Current Chemistry. 254: 41-70. DOI: http://dx.doi.org/10.1007/b100995.

[8] Friščić, T., Childs, S. L., Rizvi S. A. A., and Jones, W. 2009. The Role of Solvent in Mechanochemical and Sonochemical Cocrystal Formation: A Solubilty-Based Approach for Predicting Cocrystallization Outcome. Crystal Engineering Communication.11: 418-426. DOI: $h t t p: / / d x . d o i . o r g / 10.1039 / b 815174 a$.

[9] Maalik, A., Khan, F. A., Mumtaz, A., Mehmood, A., Azhar, S., Atif, M., Karim, S., Altaf, Y., and Tarig, I. 2014. Pharmacological Applications of Quercetin and Its Derivatives: A Short Review. Tropical Journal of Pharmaceutical Research. 13(9): 1561-1566. DOI: http://dx.doi.org/10.4314/tjpr.v13i9.26.

[10] Nguyen, T. T. H., Yu, S. H., Kim, J., An, E., Hwang, K., Park, J. S., and Kim, D. 2015. Enhancement of Quercetin Water Solubility with Steviol Glucosides and the Studies of Biological Properties. Functional Foods in Health and Disease. 5(12): 437-449.

[11] Smith, A. J., Kavuru, P., Wojtas, L., Zaworotko, M. J., and Shytle, D. 2011. Cocrystals of Quercetin with Improved Solubility and Oral Bioavailability. Molecular Pharmaceutics. 8: 1867-1876. DOI: http://dx.doi.org/10.1021/mp200209j.

[12] Vasisht, K., Chadha, K., Karan, M., Bhalla, Y., Jena, A., and Chadha R. 2016. Enhancing Biopharmaceutical Parameters of Bioflavonoid Quercetin by Cocrystallization. Cocrystal Engineering Communication. DOI: http://dx.doi.org/10.1039/C5CE01899D.

[13] Veverka, M., Dubaj, T., Gallovič, J., Jorík, V., Veverková, E. Danihelová, M., And Šimon P. 2014. Cocrystals of Quercetin: Synthesis, Characterization, and Screening of Biological Activity. Monatshefte fue Chemie. DOI: http://dx.doi.org/10.1007/s00706-014-1314-6.

[14] Setyawan, D., Oktavia, I. P., Farizka, R., and Sari, R. 2017. Physicochemical Characterization and In Vitro Dissolution Test of Quercetin-Succinic Acid Co-crystals Prepared Using Solvent Evaporation. Turkish Journal of Pharmaceutical Sciences. 14(3): 280-284. DOl: http://dx.doi.org/10.4274/tjps.16362.

[15] Ullah, M., Hussain, I., and Sun, C. C. 2016. The Development of Carbamazepine-succinic Acid Cocrystal 
Tablet Formulations with Improved in Vitro and in Vivo Performance. Drug Development and Industrial Pharmacy.

DOI: http://dx.doi.org/10.3109/03639045.2015.1096281.

[16] Khristi, A. P., Soni, T., and Suhagia, B. N. 2015. Development, Characterization and Evaluation of Sildenafil Aspirin Co-crystals. Indo American Journal of Pharmaceutical Research. 5(07): 2700-2708.

[17] Cysewski, P. 2017. In Silico Screening of Dicarboxylic Acids for Cocrystallization with Phenylpiperazine Derivatives Based On Both Cocrysttalization Propensity and Solubility Advantage. J Mol Model. 23: 136-146.

DOI: http://dx.doi.org/10.1007/s00894-017-3287-y.

[18] Davis, R. E., Lorimer, K. A., Wilkowski M. A., Rivers, J. H., Wheeler, K. A., and Bowers, J. 2004. Studies of Phase Relationships in Cocrystal Systems. ACA Transactions. 39: 41-61.

[19] Zaini, E., Halim, A., Soewandhi, S. N., Setyawan, D. 2011. Peningkatan Laju Pelarutan Trimetoprim Melalui Metode Ko-kristalisasi dengan Nikotinamida. Jurnal Farmasi Indonesia. 5(4): 205-212.

[20] Setyawan, D., Sari, R., Yusuf, H., and Primaharinastiti, R. 2014. Preparation and Characterization of ArtesunateNicotinamide Cocrystal by Solvent Evaporation and Slurry Method. Asian Journal of Pharmaceutical and Clinical Research. 7(1): 62-65.

[21] Lin, H. L., WU, T. K., and Lin, S. Y. 2014. Screening and Characterization of Cocrystal Formation of Metaxalone with Short-chain Dicarboxylic Acids Induced by SolventAssisted Grinding Approach. Thermochimica Acta. 575: 313-321.

DOI: http://dx.doi.org/10.1016/j.tca.2013.10.029

[22] Putra, O.D., Nugrahani, I., Ibrahim, S., dan Uekusa, H. 2012. Pembentukan Padatan Semi Kristalin dan Ko-kristal Parasetamol. Jurnal Matematika \& Sains. 17(2): 83-88.

[23] Scalia, S., Haghi, M., Losi, V., Trotta, V., Young, P.M., and Traini, D. 2013. Quercetin Solid Lipid Microparticles: A Flavonoid for Inhalation Lung Delivery. European Journal of Pharmaceutical Sciences. 49(2): 278-285.
DOI: $h t t p: / / d x . d o i . o r g / 10.1016 / j . e j p s .2013 .03 .009$

[24] Kakran, M., Sahoo, N. G., and Li, L. 2011. Dissolution Enhancement of Quercetin through Nanofabrication Complexation, and Solid Dispersion. Colloids and Surfaces B: Biointerfaces. 88(1): 121-130. DOI: http://dx.doi.org/10.1016/j.colsurfb.2011.06.020.

[25] Sun, C. C. 2013. Cocrystallization for Successful Drug Delivery. Expert Opinion on Drug Delivery. 10(2): 201-213. DOI: https://doi.org/10.1517/17425247.2013.747508.

[26] Friščić, T. and Jones, W. 2009. Recent Advances in Understanding the Mechanism of Cocrystal Formation via Grinding. Crystal Growth \& Design. 9(3): 1621-1637. DOI: http://dx.doi.org/10.1021/cg800764n.

[27] Momic, T., Savic, J., Cernigoj, U., Trebshe, P., and Vasic, V. 2007. Protolytic Equilibria and Photodegradation of Quercetin in Aqueous Solution. Collection of Czechoslovak Chemical Communications. 72(11): 14471460.

DOI: http://dx.doi.org/10.1135/cccc20071447.

[28] Setyawan, D., Fadhil, A. A., Juwita, D., Yusuf, H., and Sari, R. 2017. Enhancement of Solubility and Dissolution Rate of Quercetin with Solid Dispersion System Formation Using Hydroxypropyl Methyl Cellulose Matrix. Thai Journal of Pharmaceutical Sciences. 41 (3): 112-116.

[29] Karagianni, A., Malamatari, M., and Kachrimanis, K. 2018. Pharmaceutical Cocrystals: New Solid Phase Modification Approaches for the Formulation of APls. Pharmaceutics. 10: 18. DOI: http://dx.doi.org/10.3390/pharmaceutics10010018.

[30] Fotaki, N., Brown, W., Kochling, J., Chocshi, H., Miao, H., Tang, K., and Gray, V. 2013. Rationale for Selection of Dissolution Media: Three Case Studies. Dissolution Technologies. 6-13. DOI: http://dx.doi.org/10.14227/DT200313P6.

[31] Hattori, Y., Haruna, Y., and Otsuka, M. 2013. Dissolution Process Analysis Using Model-Free Noyes-Whitney Integral Equation. Colloids and Surfaces B: Biointerfaces. 102: $227-$ 231.

DOI: http://dx.doi.org/ 10.1016/j.colsurfb.2012.08.017. 